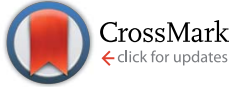

Cite this: RSC Adv., 2015, 5, 13598

Received 9th December 2014 Accepted 16th January 2015

DOI: 10.1039/c4ra16070c

www.rsc.org/advances

\section{Ternary polymer electrolytes incorporating pyrrolidinium-imide ionic liquids}

\author{
Henrik de Vries, ${ }^{\text {abc }}$ Sangsik Jeong ${ }^{\text {abc }}$ and Stefano Passerini ${ }^{\star a b c}$
}

Herein is reported the performance of ternary polymer electrolytes incorporating ionic liquids, showing higher ionic conductivity over a wide temperature range than binary polymer-salt systems, while guaranteeing higher safety compared to liquid, organic electrolytes or gel electrolytes. In particular, the electrochemical performance and the interactions between poly(ethylene oxide) (PEO), lithium bis(trifluoromethanesulfonyl)imide (LiTFSI) and several pyrrolidinium-based ionic liquids is comparatively investigated. Eight different polymer electrolytes were produced to test the ionic conductivity and longtime (more than 1400 hours) cycling stability in symmetrical lithium cells. Thermal analysis was used to investigate the thermal stability and degree of crystallinity. Six of the eight investigated samples are found fully amorphous at room temperature. In general, the properties of the polymer electrolytes are influenced by both lonic liquid ions. The ether function in the side chain of the pyrrolidinium increases the ionic conductivity but, in some cases, lowers the thermal and electrochemical stability.

\section{Introduction}

Polymer electrolytes are well known and established in the research field of lithium batteries. ${ }^{1}$ They are cheap and safe, and act as electrolyte, separator and binder in one. Furthermore, they guarantee a stable operation with lithium metal anodes, which is not true for liquid, carbonate-based electrolytes. ${ }^{2}$ The most popular polymer is poly(ethylene oxide), PEO, due to its high lithium ion conductivity and good electrochemical and chemical stability, especially with the lithium metal electrode. ${ }^{3}$ In industrial applications binary systems are already used, in which the polymer is combined with a conductive salt. While the salt cations $\left(\mathrm{Li}^{+}\right.$ions) supplies the electroactive species in the electrolyte, the anions might additionally exert a plasticizing effect on the polymer when they have low charge density, high flexibility and large hindrance (e.g., bis(trifluoromethanesulfonyl)imide a.k.a. TFSI). ${ }^{4}$ The main issue which prevents the use of these electrolyte systems in more applications is the low ionic conductivity at room temperature. This is caused by the limited mobility of the PEO chains, which support the cation mobility. In practice, PEO-based electrolytes are only conductive when the polymer is in the amorphous state. ${ }^{3}$ To solve this problem, cells are usually run at high temperatures over the melting point of PEO (e.g., at $\left.80{ }^{\circ} \mathrm{C}\right)$. Although such a strict requirement, PEO-based cells are successfully used in the

${ }^{a}$ Institute of Physical Chemistry, University of Muenster, Corrensstrasse $28 / 30 \& 46$, 48149 Muenster, Germany. E-mail: Stefano.passerini@kit.edu

${ }^{b}$ Helmholtz Institute Ulm (HIU), Helmholtzstrasse 11, 89081 Ulm, Germany ${ }^{c}$ Karlsruhe Institute of Technology (KIT), P.O. Box 3640, 76021 Karlsruhe, Germany
Bolloré Bluecar, which has been deployed as part of the Autolib' carsharing program in Paris, since December 2011. ${ }^{5}$

In an attempt to address the high operative temperature issue of available polymer electrolytes, in 1996 Watanabe and colleagues proposed the incorporation of an ionic liquid mixture of two lithium salts (lithium acetate and LiTFSI) and triethylmethylammonium benzoate (TEMAB) into polyacrylonitrile or poly(vinyl butyrate), yielding to a polymer electrolyte with enhanced ionic conductivity. ${ }^{6}$ However, though complexation of the ionic liquid and polymer was reported, recrystallization and phase separation occurred after some time. No further investigation on the ionic liquid-polymer interaction was performed, however, it is very reasonable to assume that the liquid phase was just trapped within the polymer matrix, forming a self-standing polymer gel electrolyte, with the $\mathrm{Li}^{+}$ions moving in the liquid phase.

In 2003, we have found that ternary mixtures of PEO, LiTFSI and $N$-alkyl- $N$-methylpyrrolidinium bis(trifluoromethanesulfonyl)imide, a.k.a. Pyr $_{1 \mathrm{~A}}$ TFSI, form electrolytes with high ionic conductivity even at room temperature. ${ }^{7}$ In following studies, we have demonstrated as such ternary electrolytes show excellent performance in terms of plating and stripping from lithium metal electrodes. ${ }^{8}$ Prototypes using these ternary electrolytes were developed and proved to operate at moderate rate $(\mathrm{C} / 5$ and $\mathrm{C} / 3)$ at $40^{\circ} \mathrm{C}$ and at low rate $(\mathrm{C} / 20)$ even at $20^{\circ} \mathrm{C} .{ }^{9}$ The major hurdle limiting the room temperature performance was identified in the high value of the resistance at the lithium/ polymer electrolyte interface. ${ }^{9}$ As an alternative approach poly-ionic liquids have been proposed, ${ }^{\mathbf{1 0 - 1 2}}$ some of them including ethylene oxide units. ${ }^{\mathbf{1 1} 12}$ However, their ionic conductivity is, at the best, only comparable to the cheaper and 


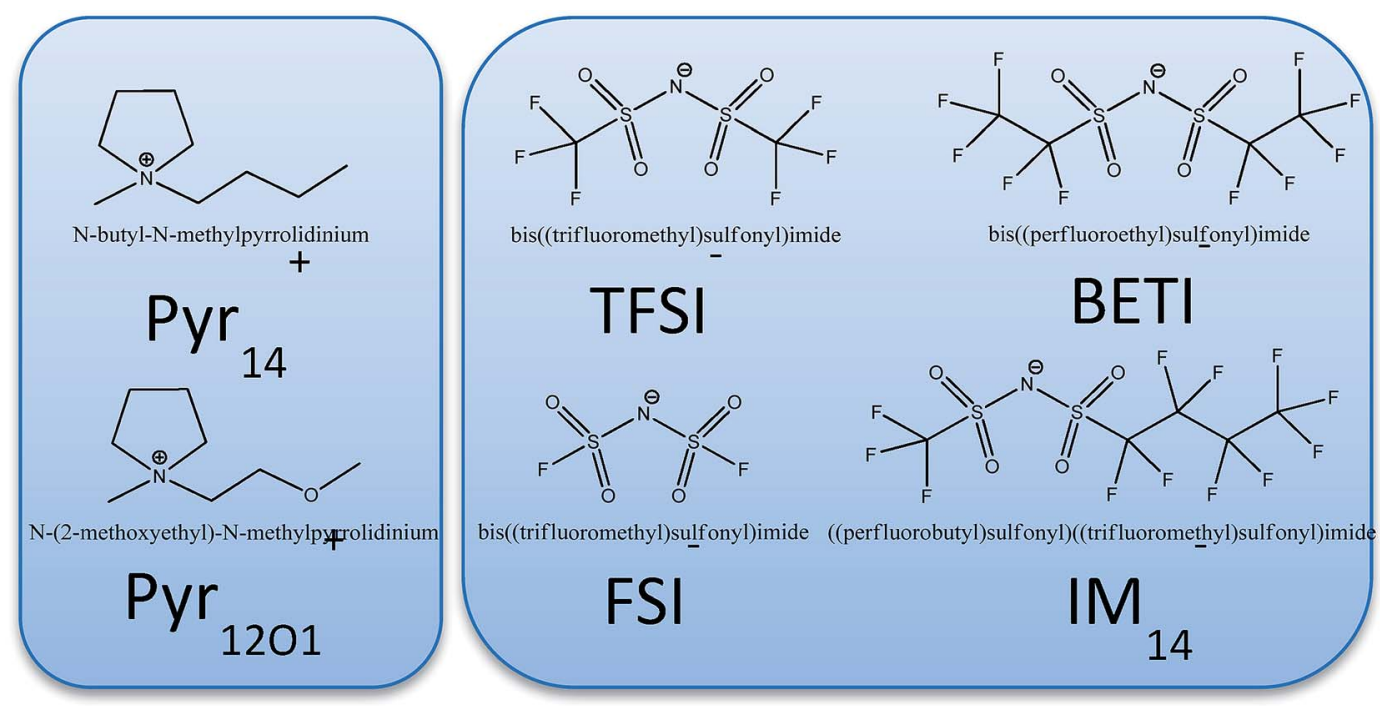

Fig. 1 Pyrrolidinium cations (left) and perfluorinated imide anions (right) composing the ionic liquids investigated in this work.

easier to make cross-linked ternary polymer electrolytes herein presented.

The conductivity improvement of PEO-LiTFSI-PYR ${ }_{1 \mathrm{~A}}$ TFSI at low temperatures is associated to the enhanced lithium mobility in the solid phase, resulting from the plasticisation of the polymer induced by the presence of the additional TFSI anions balancing the (rather non-interacting) pyrrolidinium cations. $^{8}$ In a recent study we have presented a three-phase diagram outlining the compositions in which ternary polymer electrolytes exist in the fully amorphous state at room temperature. ${ }^{13}$

In this work the system is expanded to mixtures of PEO and LiTFSI with one of eight different ionic liquids synthesized combining different cations and fluorinated sulfonylimides (Fig. 1). The cation is either $N$-butyl- $N$-methylpyrrolidinium $\left(\mathrm{Pyr}_{14}\right)$ or $N$-methoxy-ethyl- $N$-methylpyrrolidinium $\left(\mathrm{Pyr}_{1201}\right)$. In this latter one oxygen with two free electron pairs replace $\mathrm{a} \mathrm{CH}_{2}-$ group. In addition to TFSI, three different perfluorinated anions, FSI (bisfluorosulfonylimide; $\left(\mathrm{FSO}_{2}\right)_{2} \mathrm{~N}^{-}$), BETI (bis(pentafluoroethanesulfonyl)imide; $\left(\mathrm{C}_{2} \mathrm{~F}_{5} \mathrm{SO}_{2}\right)_{2} \mathrm{~N}^{-}$), and $\mathrm{IM}_{14}$ ((nonafluorobutanesulfonyl) (trifluoromethanesulfonyl)imide; $\left.\left.\left(\mathrm{C}_{4} \mathrm{~F}_{9} \mathrm{SO}_{2}\right)\left(\mathrm{CF}_{3} \mathrm{SO}_{2}\right) \mathrm{N}^{-}\right)\right)$, were used to investigate their effect on the ternary polymer electrolytes. All ionic liquids used were inhouse synthesized, purified and electrochemically characterized. ${ }^{14}$ However, with the exception of $\mathrm{Pyr}_{14}$ TFSI, which is used as a baseline and is known to yield to the best performing polymer electrolyte system at the state of the art, they have never been used in polymer electrolytes.

\section{Experimental}

Eight different polymer electrolytes were produced as described before..$^{15}$ Briefly, PEO (Dow Chemicals, WSR 301, MW $=4$ Mio) and LiTFSI ( $3 \mathrm{M}$, battery grade, vacuum dried $\left[10^{-7} \mathrm{mbar}\right]$ for 48 $\mathrm{h}$ at $110{ }^{\circ} \mathrm{C}$ ) were dry-mixed. A mixture of benzophenone (Aldrich, $5 \mathrm{wt} \%$ based on PEO) and one of the eight ionic liquids was then added. After annealing the mixtures at $80{ }^{\circ} \mathrm{C}$ under vacuum, self-standing polymer electrolyte films were obtained by hot pressing the composites at $100{ }^{\circ} \mathrm{C}$. The molar ratio of PEO : LiTFSI : ionic liquid was always $20: 2: 4$, which is known to form stable, amorphous films with $\mathrm{Pyr}_{14}{ }_{14}$ TFSI. ${ }^{13}$ Finally, the polymer films were cross-linked by UV radiation for 10 minutes (Hönle UVA Cube 100).

Thermo-gravimetrical analyses was performed in oxygen and nitrogen gas. The stability of the different electrolytes was investigated using a thermogravimetric analyser (TGA; TA Instruments Model Q5000). The samples were hermetically sealed in aluminium pans inside a dry room (dew point: $-60{ }^{\circ} \mathrm{C}$ ). The TGA device punched the pans automatically prior to the measurement. After a purge step with the reaction gas, the temperature was ramped $\left(5 \mathrm{~K} \mathrm{~min}^{-1}\right)$ from room temperature to $600{ }^{\circ} \mathrm{C}$. The sample weight change with time and temperature was recorded.

Differential scanning calorimetry (DSC; TA Instruments Model Q2000) was used to investigate melting and glass transition temperatures. Aluminium pans were filled in the dry room and remained sealed during the measurement. The samples were first quenched to $140{ }^{\circ} \mathrm{C}$. Afterwards, three heating-cooling cycles were recorded between -140 and $200^{\circ} \mathrm{C}$ with $5 \mathrm{~K} \mathrm{~min}^{-1}$.

Ionic conductivity was measured in symmetrical pouch cells. Polymer electrolytes films with an area of $4 \mathrm{~cm}^{2}$ were placed between two copper foils. The thickness of the polymer electrolyte films ranged between 80 and $120 \mu \mathrm{m}$. The cells were stored in a climatic chamber (Binder) and electrochemical impedance analysis (EIS) was performed with an impedance analyser (Solartron 1260). After every measurement the temperature was changed in $10{ }^{\circ} \mathrm{C}$ steps allowing the cells to stabilize for $24 \mathrm{~h}$. A heating $\left(20^{\circ} \mathrm{C}\right.$ to $\left.80^{\circ} \mathrm{C}\right)$ followed by a cooling $\left(20{ }^{\circ} \mathrm{C}\right.$ to $\left.-40{ }^{\circ} \mathrm{C}\right)$ test series were performed. To control the effect of the thermal history, a third measurement at $20^{\circ} \mathrm{C}$ was always done afterwards. 
Cycling tests were performed in symmetrical lithium pouch cells. Polymer electrolytes films with an area of $4 \mathrm{~cm}^{2}$ were placed between two lithium foils (Rockwood Lithium, $50 \mu \mathrm{m}$ ). The cycling tests were done in a climatic chamber (Binder) at $40{ }^{\circ} \mathrm{C}$ with a Maccor battery cycler. For limiting current tests, several potential steps were applied for $10 \mathrm{~h}$ each: $0.02 ; 0.05 ; 0.1$ and $0.2 \mathrm{~mA} \mathrm{~cm}^{-2}$; afterwards the potential was increased by $0.2 \mathrm{~mA} \mathrm{~cm}{ }^{-2}$ in each step until the evolution of the cells potential indicated the decomposition of the electrolyte. The polarization of the cell was not changed during the test. However, after every current step a $10 \mathrm{~h}$ rest time was included for relaxation of the cell potential.

\section{Results}

\section{Thermal analysis}

The thermal stability was investigated in both oxidizing $\left(\mathrm{O}_{2}\right)$ and inert $\left(\mathrm{N}_{2}\right)$ atmospheres. Due to the very low vapour pressure and the high thermal stability of ionic liquids, only very small weight loss is detected at low temperature caused by the release of benzophenone and its photochemical reaction products.

The thermal gravimetric analysis proves the high thermal stability of the ternary polymer electrolytes in inert atmosphere (Fig. 2). The TGA curves show as electrolytes with $\mathrm{Pyr}_{14}$ and $\operatorname{Pyr}_{1201}$ cation have practically the same stability. However, while the samples containing TFSI anions and mixtures with BETI or
$\mathrm{IM}_{14}$ anions are stable up to $300{ }^{\circ} \mathrm{C}$ those containing the FSI anion appear more reactive (i.e., less thermally stable). However, no weight loss was observed up to $200{ }^{\circ} \mathrm{C}$ even in the presence of the FSI anion.

The samples containing TFSI, BETI and $\mathrm{IM}_{14}$ anions show a two-step decomposition mechanism in nitrogen. The weight loss during the $1^{\text {st }}$ step is most likely caused by PEO decomposition, followed by LiTFSI and ionic liquid decomposition. ${ }^{8,13}$ For the FSIcontaining electrolytes three steps can be observed. The lower stability of these samples is caused by the ionic liquid anion which is much more reactive. It is known that in a mixture of Pyr $_{14}$ FSI and LiTFSI in situ formation of LiFSI takes place. While the pure ionic liquid $\mathrm{Pyr}_{14}$ FSI shows only a small weight loss at $200{ }^{\circ} \mathrm{C}$ and a fast decomposition between 280 and $300{ }^{\circ} \mathrm{C},{ }^{16} \mathrm{LiFSI}$ salt decomposes at $183{ }^{\circ} \mathrm{C}$; Huang and Hollenkamp proposed a possible decomposition reaction under dry conditions. ${ }^{17}$ The decomposition products of FSI may catalyse the decomposition of PEO (31.7 wt\% in electrolyte) in the $1^{\text {st }}$ step, followed by decomposition of the remaining components in two steps.

The ternary polymer electrolytes show high thermal stability even in oxidizing atmosphere (Fig. 3). All samples are stable up to $200{ }^{\circ} \mathrm{C}$ with only small weight loss taking place below $100{ }^{\circ} \mathrm{C}$. In this case, the FSI-based electrolytes do not decompose earlier compared to the other samples, indicating that the occurring decomposition at temperatures below $100{ }^{\circ} \mathrm{C}$ is related to a
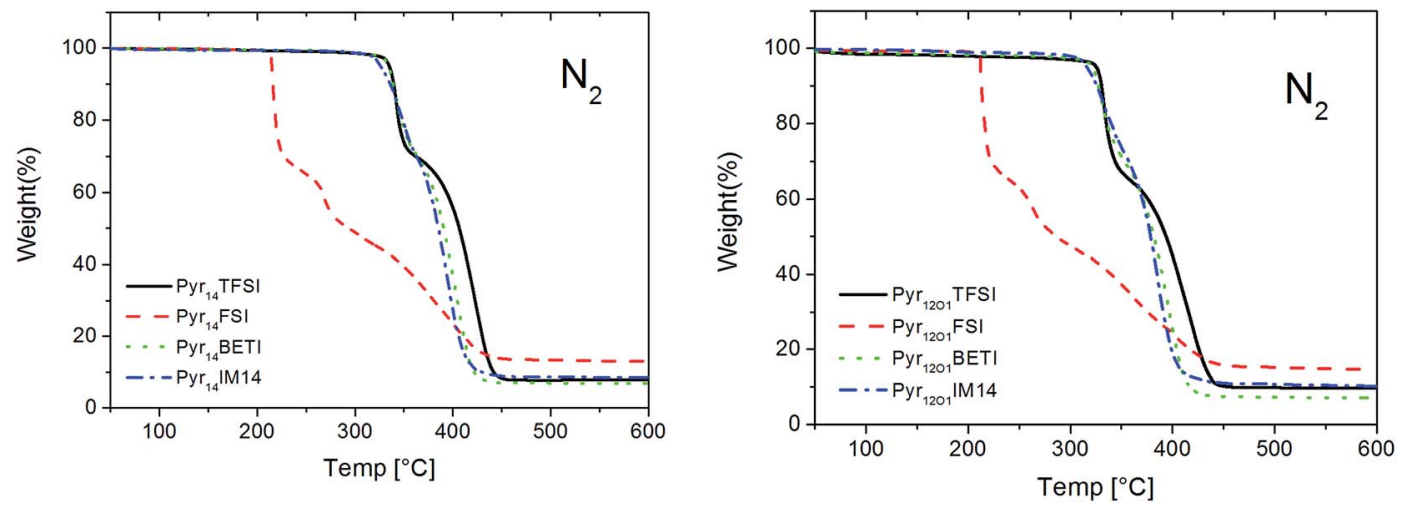

Fig. 2 TGA of polymer electrolytes in inert atmosphere. Scan rate $5{ }^{\circ} \mathrm{C} \mathrm{min}^{-1}$.
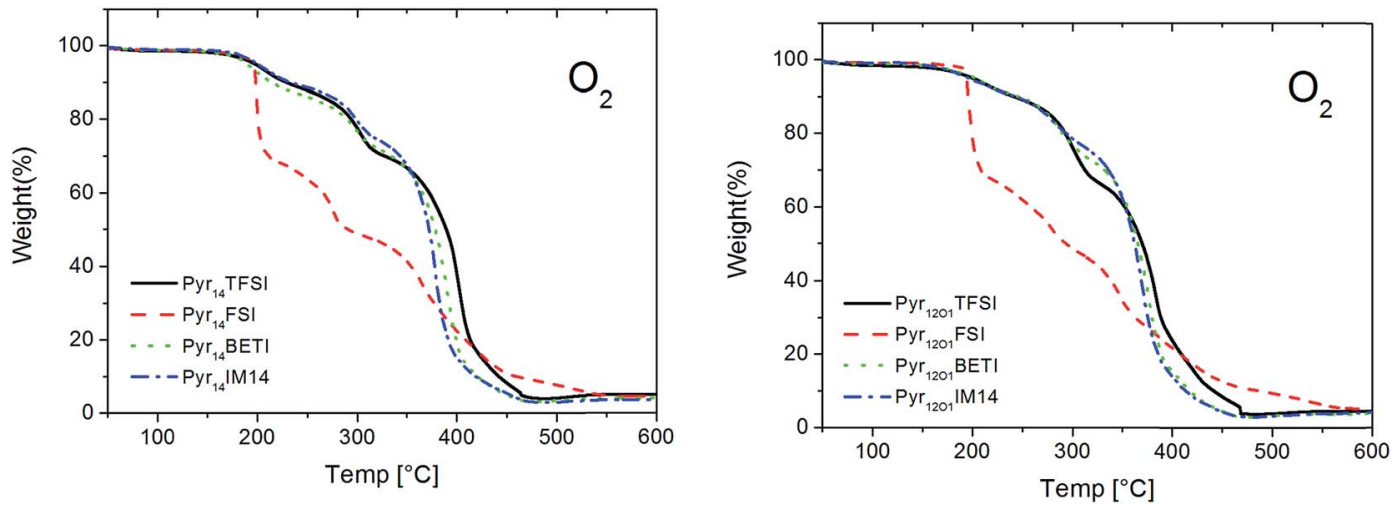

Fig. $3 \mathrm{TGA}$ of the polymer electrolytes in oxygen atmosphere. Scan rate $5^{\circ} \mathrm{C} \mathrm{min}^{-1}$. 
common component rather than the FSI anion. Although we did not pursue the identification of such a component, we fell reasonably to propose the oxidation of the reacted benzophenone (used as cross-linking initiator) as the cause of the weight loss at below $100{ }^{\circ} \mathrm{C}$. Nevertheless, the FSI-containing samples own a lower thermal stability as evidenced by the fastest weight loss at higher temperature.

DSC investigation was performed to estimate the effect of the ionic liquid on the morphology of the polymer electrolytes. DSC measurements, in fact, can supply information about the amorphicity of the polymer electrolytes, which would improve the ionic conductivity of the system, and the effect the ionic liquid has on the glass transition temperature $\left(T_{\mathrm{g}}\right)$. The latter information is rather important since at temperatures below the $T_{\mathrm{g}}$ no movement in the polymer takes place. Thus, the lower the $T_{\mathrm{g}}$, the higher is the ionic conductivity at room temperature expected to be. ${ }^{18}$

Fig. 4 reveals that the glass transition temperature of the polymer electrolytes depends on the anion. Additionally, the polymers including TFSI anions or mixtures with BETI or IM IM $_{14}$ anions are fully amorphous while those containing FSI show the existence of crystalline phases indicated by the several peaks in the DSC curves between $0{ }^{\circ} \mathrm{C}$ and $100{ }^{\circ} \mathrm{C}$. This is, indeed, in accordance with the appearance of the electrolytes, which look transparent when containing the TFSI, BETI, and $\mathrm{IM}_{14}$ anions, but exhibit opacity with the FSI anion. The glass transition temperatures measured during the $2^{\text {nd }}$ heating and cooling scan are presented in Table 1.

The comparison of the different anions shows as the $T_{\mathrm{g}}$ for FSI-containing samples are much lower than for the other samples, although the former ternary electrolytes have shown crystallization melting features above ambient temperature. Considering the effect of the ionic liquid cation, it is seen as Pyr $_{14}$ TFSI offers a slightly lower $T_{\mathrm{g}}$ than $\mathrm{Pyr}_{12 \mathrm{O} 1}$ TFSI while the contrary is observed for all other anions (FSI, BETI and $\mathrm{IM}_{14}$ ).

\section{Ionic conductivity}

The ionic conductivity was measured in symmetrical $\mathrm{Cu}$ cells using AC impedance spectroscopy in the temperature range between $-40{ }^{\circ} \mathrm{C}$ and $80{ }^{\circ} \mathrm{C}$. The following equation was used to calculate the overall ionic conductivity $\sigma_{\mathrm{El}}$ from the electrolyte bulk resistance, which was taken as the high frequency intercept in the Nyquist plot of the impedance measurements (not shown):

$$
\sigma_{\mathrm{El}}=\frac{d}{A \times R_{\mathrm{El}}}
$$

The thickness $d$ of the polymer electrolyte films was around $100 \mu \mathrm{m}( \pm 20 \mu \mathrm{m})$ while the electrode area was $4 \mathrm{~cm}^{2}$.

The Arrhenius plots in Fig. 5 present the ionic conductivity (net charge transport of all ionic species) of the eight polymer electrolytes. All samples show a conductivity higher than $10^{-4} \mathrm{~S} \mathrm{~cm}^{-1}$ at room temperature and $10^{-3} \mathrm{~S} \mathrm{~cm}^{-1}$ at $60{ }^{\circ} \mathrm{C}$.

Binary PEO-LiTFSI polymer electrolytes show a jump in conductivity (sometimes including the switch from Arrhenius to VTF behaviour) when the melting of the crystalline PEO and PEO-Li salt phases takes place. ${ }^{8}$ However, this behaviour is not observed for the eight ternary electrolytes in this study because they are fully amorphous with the exception of the samples containing FSI. In fact, these samples are partly crystalline as indicated by the distinct melting features observed with DSC
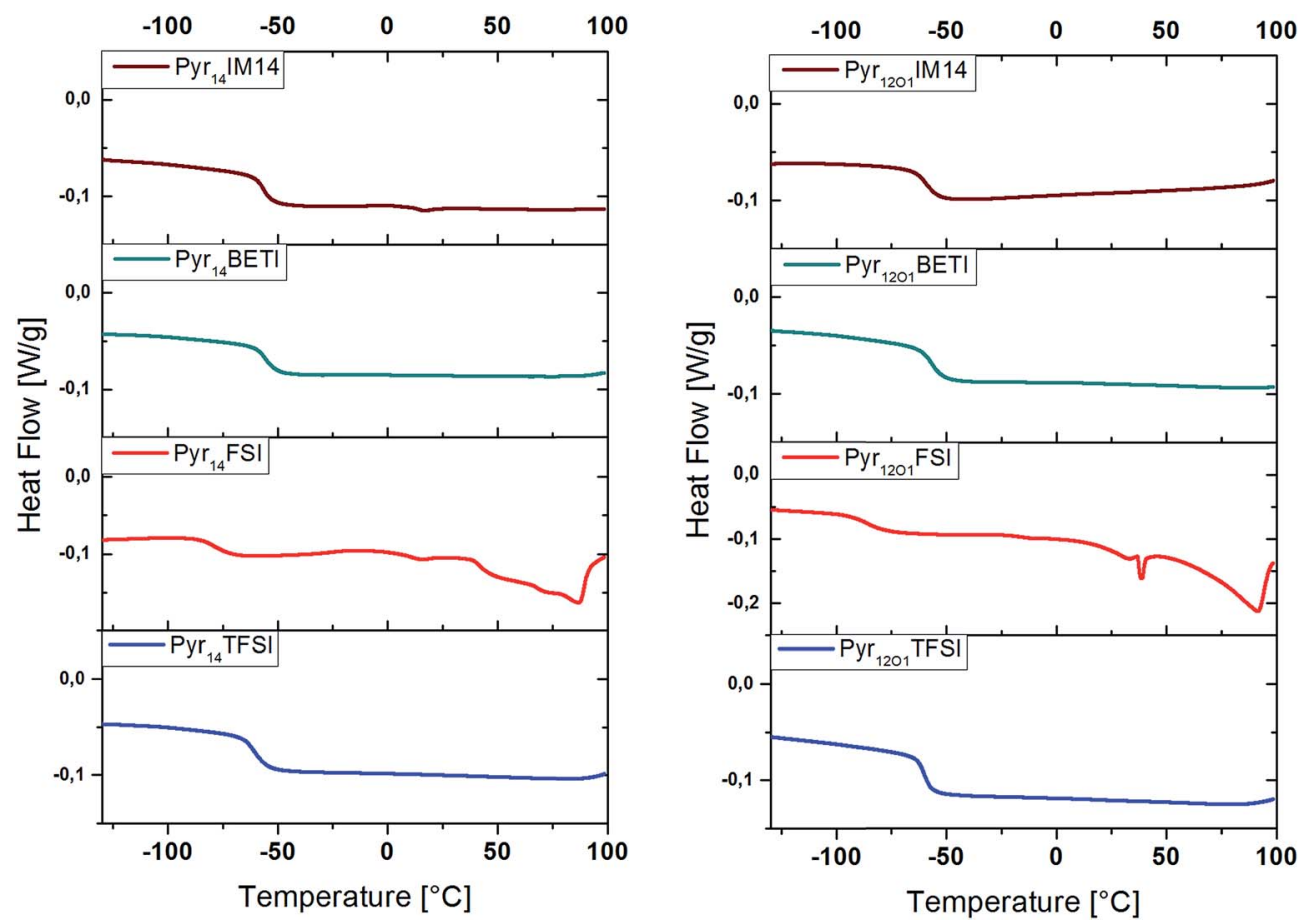

Fig. 4 DSC of polymer electrolytes, $5 \mathrm{~K} \mathrm{~min}^{-1}, 1^{\text {st }}$ heating scan, exothermic heat up. 
Table 1 Glass transition temperature during $2^{\text {nd }}$ heating/cooling cycle $\left(5 \mathrm{~K} \mathrm{~min}^{-1},-140 / 100^{\circ} \mathrm{C}\right)$

\begin{tabular}{lll}
\hline Ionic liquid & $T_{\mathrm{g}}$ heating $\left[{ }^{\circ} \mathrm{C}\right]$ & $T_{\mathrm{g}}$ cooling $\left[{ }^{\circ} \mathrm{C}\right]$ \\
\hline Pyr $_{14}$ TFSI & -61.8 & -67.2 \\
Pyr $_{14}$ FSI & -79.8 & -88.9 \\
Pyr $_{14}$ BETI & -56.6 & -62.1 \\
Pyr $_{14}$ IM14 & -57.0 & -62.2 \\
12O1_TFSI & -60.2 & -63.1 \\
12O1_FSI & -85.3 & -93.2 \\
12O1_BETI & -58.1 & -64.8 \\
12O1_IM14 & -59.8 & -65.9
\end{tabular}

investigation. However, the melting of the crystalline fraction does not have a huge impact on the overall conductivity since no net transition is observed in the Arrhenius graphs.

The protocol used for the conductivity measurements allow us to control if the thermal history affects the polymer electrolyte conductivity. In fact, three data points were acquired at $20{ }^{\circ} \mathrm{C}$ for each sample, which are all reported in the graphs. They were recorded at the beginning of the heating scan, before the successive cooling scan (i.e., after cooling from the heating scan to $80^{\circ} \mathrm{C}$ ) and upon thermal equilibration after the cooling scan to $-40^{\circ} \mathrm{C}$. For both FSI-containing samples the conductivity at $20^{\circ} \mathrm{C}$ is seen to increase throughout the test series. The increase from the first to the second data point was somehow expected as a result of slow recrystallization kinetics after the heating scan to $80^{\circ} \mathrm{C}$. However, the increase detected with the third measurement is very surprising, since the crystallinity of these electrolytes should have increased after the cooling to $-40{ }^{\circ} \mathrm{C}$. In fact, DSC measurements show a few endothermic peaks starting from $0{ }^{\circ} \mathrm{C}$ up to almost $100{ }^{\circ} \mathrm{C}$ upon the heating cycle with corresponding crystallization features between $50{ }^{\circ} \mathrm{C}$ and $0{ }^{\circ} \mathrm{C}$ during cooling (Fig. 6). Therefore, a small crystalline fraction should be present at $20{ }^{\circ} \mathrm{C}$, causing lower ionic conductivity. This is suggesting that the thermal history might affect the measured conductivity of those polymer electrolytes containing the FSI anion. However, no effect was observed for all other ternary electrolytes.

The overall ionic conductivity results from the charge transport of all ionic species - in this case the $\mathrm{Li}^{+}$and pyrrolidinium cations as well as the anions. To evaluate the specific lithium ion conductivity symmetrical lithium cells were assembled and cycled with two different test protocols each addressing the maximum steady-state current sustained by the electrolyte or the lithium plating/stripping performance.

The maximum steady-state current sustained by the polymer electrolytes was investigated by applying increasing potential steps, each for several hours. For each step the steady-state current was determined to depend on the applied potential. At some point, however, the steady-state current is expected not to rise upon increasing potential, this representing the limiting current of the electrolyte. This test also reveals relaxation processes and eventual decomposition reactions of the electrolyte (i.e., electrochemical stability $v s$. lithium).

In more details, symmetrical lithium cells were step-wise polarized (for $10 \mathrm{~h}$ ) at increasing potentials, intermixed with $10 \mathrm{~h}$ relaxation steps. The voltage of the cell was recorded. With increasing potential the cells take longer to reach the steadystate current, i.e., the condition in which the current is sustained only by the electroactive ionic species $\left(\mathrm{Li}^{+}\right)$and is then limited by the lithium ions diffusion into the electrolyte.

Three of the potential steps are presented in Fig. 7. At $40{ }^{\circ} \mathrm{C}$ and $0.2 \mathrm{~V}$ polarization, the two samples containing FSI anions show the lowest current densities, $0.01 \mathrm{~mA} \mathrm{~cm}^{-2}$ for $\mathrm{Pyr}_{1201} \mathrm{FSI}$ and $0.02 \mathrm{~mA} \mathrm{~cm}{ }^{-2}$ for $\mathrm{Pyr}_{14} \mathrm{FSI}$, although they exhibit the highest overall ionic conductivity, as evidenced by conductivity measurements. Such a poor performance indicates that the total ionic conductivity in FSI-based polymer electrolytes is mostly contributed by the small FSI anions rather than the strongly coordinated (by PEO) $\mathrm{Li}^{+}$cations, although some effects due to the formation of a rather thick SEI layer on the lithium electrodes cannot be excluded. The two BETIcontaining electrolytes show much better performance which was independent on the IL cation, with current density of more
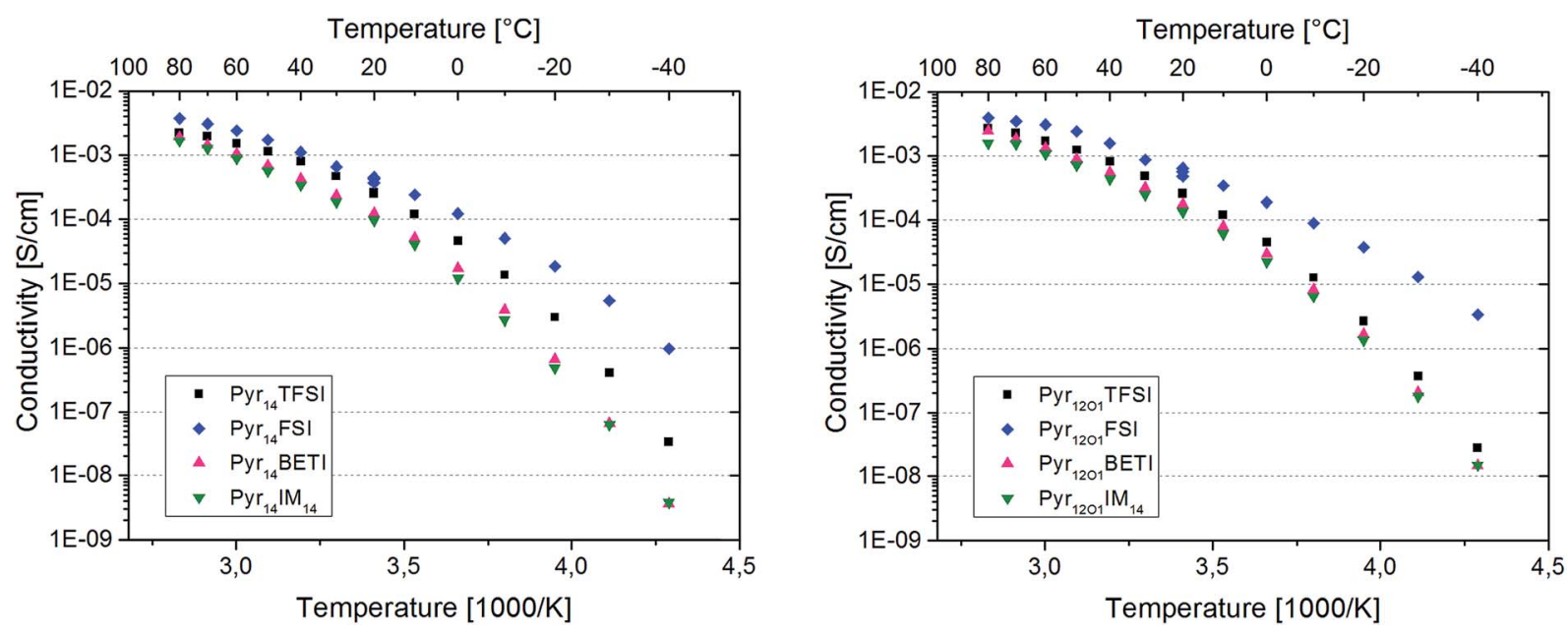

Fig. 5 Arrhenius plot for $\mathrm{Pyr}_{14}$ - (left side) and $\mathrm{Pyr}_{12 \mathrm{O}}$ - (right side) containing electrolytes. 


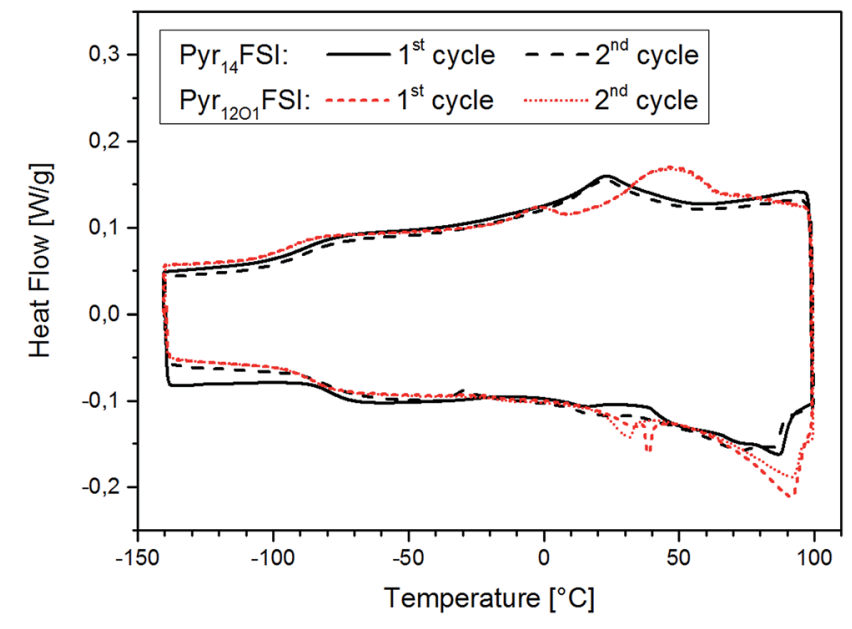

Fig. 6 DSC curves of $\mathrm{Pyr}_{14} \mathrm{FSI}$ - and $\mathrm{Pyr}_{1201} \mathrm{FSI}$-containing electrolytes, $1^{\text {st }}$ and $2^{\text {nd }}$ heating/cooling cycle, exothermic heat up.

than $0.03 \mathrm{~mA} \mathrm{~cm}{ }^{-2}$. Even better is the performance of $\mathrm{IM}_{14^{-}}$ based electrolytes with the one containing $\mathrm{Pyr}_{1201} \mathrm{IM}_{14}$ approaching $0.05 \mathrm{~mA} \mathrm{~cm}^{-2}$. However, the highest steady-state current densities were achieved with those electrolytes containing TFSI only, especially that with $\operatorname{Pyr}_{14}$ TFSI $\left(0.06 \mathrm{~mA} \mathrm{~cm}^{-2}\right)$.

With increasing potential the current density increased for all samples. The electrolyte containing $\mathrm{Pyr}_{12 \mathrm{O} 1} \mathrm{FSI}$ is still showing the worst performance though its steady-state current density doubled. For the one with $\mathrm{Pyr}_{14} \mathrm{FSI}$ a three-fold increase in current density, to more than $0.065 \mathrm{~mA} \mathrm{~cm}^{-2}$, is observed. For the $\mathrm{Pyr}_{14} \mathrm{IM}_{14}$-containing electrolyte, however, the polarization increase resulted in an increase of only about $75 \%$ (to $0.06 \mathrm{~mA} \mathrm{~cm}^{-2}$ ). A much higher value was reached with
Pyr $_{14}$ BETI (increased by a factor of 3 ) as well as $\operatorname{Pyr}_{1201}$ TFSI (increased by a factor of 2) with around $0.1 \mathrm{~mA} \mathrm{~cm}{ }^{-2}$. The highest current densities $\left(0.125 \mathrm{~mA} \mathrm{~cm}^{-2}\right)$ were achieved with $\mathrm{Pyr}_{14}$ TFSI, Pyr ${ }_{1201}$ BETI and $\mathrm{Pyr}_{1201} \mathrm{IM}_{14}$. It is noticeable, however, that the current flowing through the $\mathrm{Pyr}_{14}$ TFSIcontaining electrolyte did never reach the steady state, as indicated by the continuous current density decline.

With the applied potential of $1 \mathrm{~V}$, the $\mathrm{Pyr}_{12 \mathrm{O} 1}$ electrolytes with small anions (FSI and TFSI) show signs of electrochemical decomposition. This is somehow surprising since TFSI is known as a electrochemically very stable anion. However, the decomposition might very well involve the ionic liquid cation, instead, although the electrolytes incorporating $\operatorname{Pyr}_{1201}$ and BETI or $\mathrm{IM}_{14}$ show no signs of decomposition. The highest current density $-0.14 \mathrm{~mA} \mathrm{~cm}^{-2}$ - in this test series was reached with $\mathrm{Pyr}_{12 \mathrm{O} 1} \mathrm{BETI}$, with $\mathrm{Pyr}_{12 \mathrm{O} 1} \mathrm{IM}_{14}$ having the second highest value $\left(0.125 \mathrm{~mA} \mathrm{~cm} \mathrm{~cm}^{-2}\right)$. Also noticeable is the continuous current density decline observed for the electrolyte containing $\mathrm{Pyr}_{14}$ TFSI, which supports degradation phenomena to occur at the polymer electrolyte-lithium interface resulting in a continuous increase of the interfacial resistance.

To better delimitate the range of stability of this latter polymer electrolyte, the time evolution of the current density curves, as well as the potential curves recorded during the relaxation steps are presented in Fig. 8. From the graphs is it observed that the continuous decline of the current density already starts at $0.6 \mathrm{~V}$, although at a minor extent, to become very substantial at $0.8 \mathrm{~V}$. Also, after the $1 \mathrm{~V}$ step the cell does not reach the $0 \mathrm{~V}$ during the following relaxation. This is a clear sign for the occurrence of decomposition reactions leading to the growth of a rather thick passivation layer at the lithium/electrolyte interface. This result indicates that $\mathrm{Pyr}_{14}$ TFSI-containing polymer electrolytes should
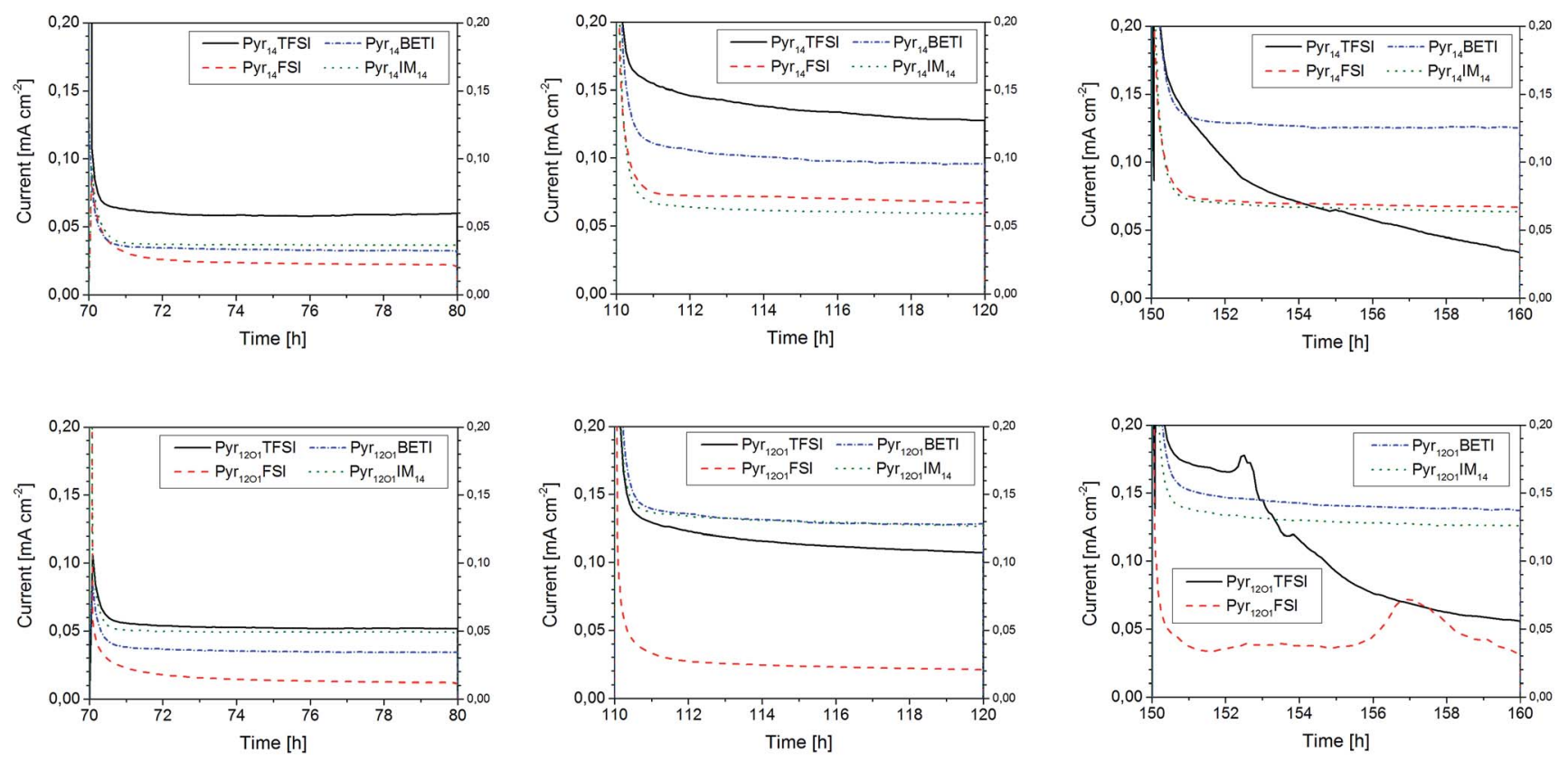

Fig. 7 Chronoamperometry curves upon $10 \mathrm{~h}$ polarization steps (intermixed with $10 \mathrm{~h}$ relaxation steps) at $0.2 \mathrm{~V}$ (left), $0.6 \mathrm{~V}$ (center) and $1.0 \mathrm{~V}$

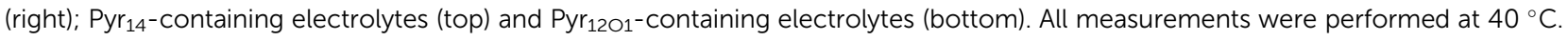



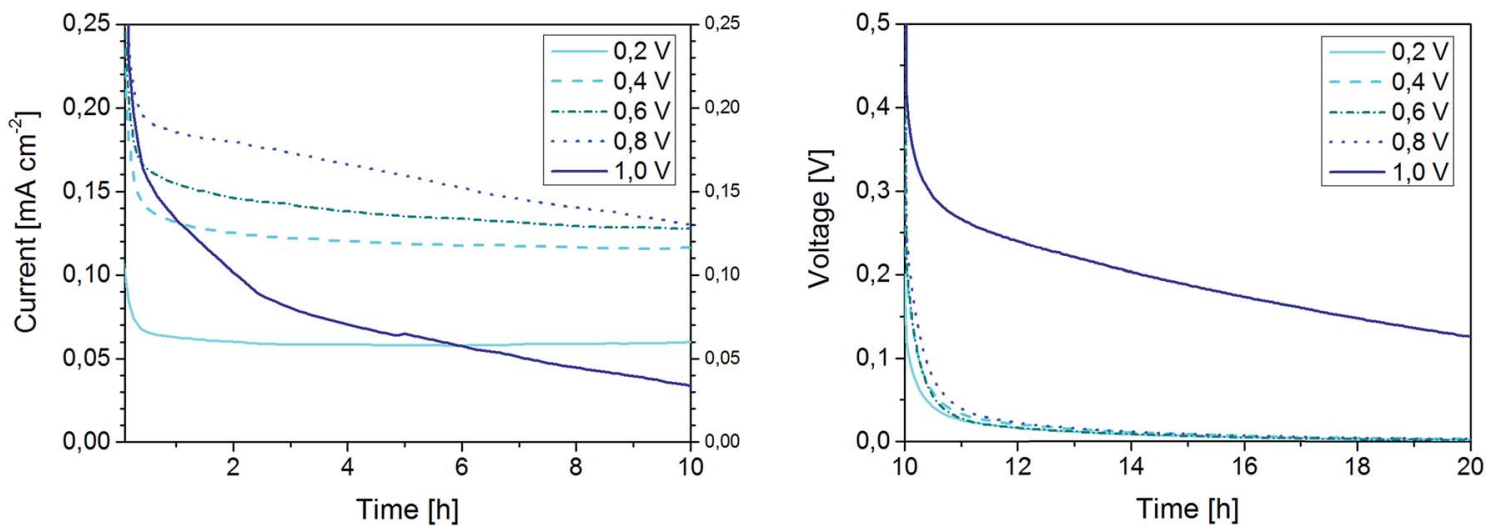

Fig. 8 Chronoamperometry curves at various voltages (left panel) as detected upon $10 \mathrm{~h}$ polarization steps applied to the Pyr ${ }_{14}$ TFSi-containing polymer electrolyte in symmetric lithium cells $\left(T=40^{\circ} \mathrm{C}\right)$. The cell voltage relaxation recorded during the intermixed rest steps are also reported (right).

not be used at current densities higher than $0.12 \mathrm{~mA} \mathrm{~cm}^{-2}$ (at $40^{\circ} \mathrm{C}$ ) in order to avoid elevated overvoltages which would result in the electrolyte decomposition. Slightly higher current densities can be achieved using the $\mathrm{Pyr}_{12 \mathrm{O} 1}$ BETI-containing electrolyte.

Galvanostatic cycling tests were performed to investigate the long-term lithium stripping-plating performance. Freshly deposited lithium is extremely reactive, resulting in the occurrence of electrolyte decomposition reactions, in turns leading to lithium consumption (cell capacity loss) and SEI formation during cycling (increased internal cell resistance) ${ }^{2 a, 19}$ For these tests a specific current, which sign is reversed every hour, is applied to the cell and the overvoltage recorded. The evolution of overpotential can be used to monitor the SEI evolution (the increase of the internal resistance results in the increase of the overvoltage) while the overall number of cycles is limited by the lithium consumption during cycling or short-circuits caused by lithium dendrite growth. In order to perform this experiment in a reasonable amount of times (usually a few months) it is
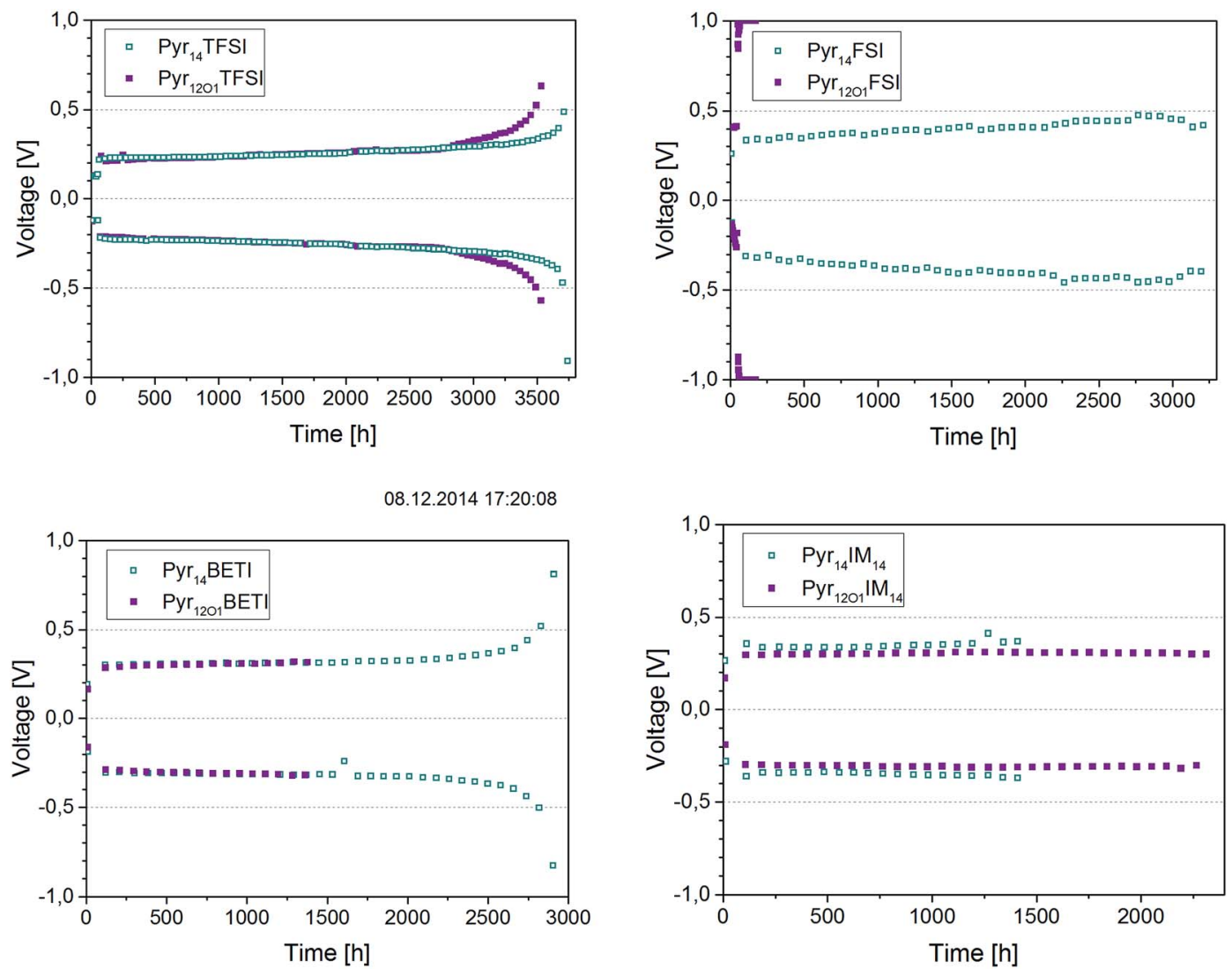

Fig. 9 Stripping-plating in symmetrical lithium cells at $0.1 \mathrm{~mA} \mathrm{~cm}-2$ and $40{ }^{\circ} \mathrm{C}$. The ionic liquid present in the electrolytes is indicated in the legends. 
important to use rather thin lithium foils (here: $50 \mu \mathrm{m}$ ) to limit the lithium reservoir.

The stripping-plating tests were performed by reversing the polarization of the cells every hour. A current density of $0.1 \mathrm{~mA} \mathrm{~cm}^{-2}$ was chosen since this value was achieved with most of the electrolytes (except $\mathrm{Pyr}_{12 \mathrm{O} 1} \mathrm{FSI}$ ) at $40{ }^{\circ} \mathrm{C}$. The cells were stopped after $10,20,50,100,200,400,600,800$ and 1000 cycles for impedance measurements $\left(21^{\circ} \mathrm{C}\right)$ in order to evaluate the changes of the electrolyte and interfacial resistances. The overvoltage evolution upon cycling (cell potential at the end of $1 \mathrm{~h}$ polarization) for all cells is shown in Fig. 9.

The expected behaviour for this test is exemplarily shown by the $\mathrm{Pyr}_{14}$ BETI-containing electrolyte. In the first initial cycles the overvoltage increases resulting from the establishment of the interfaces between the electrolyte and both electrodes. In the following few thousand cycles the overvoltage is practically constant. However, a small fraction of freshly deposited lithium is consumed at each cycle, resulting, after 2500 hours, in the rapid increase of the overvoltage due to the scarcity of lithium available for stripping.

According to the results in Fig. 9 the best performing electrolyte in this test was that incorporating Pyr $_{14}$ TFSI (i.e., the TFSI anion only). This electrolyte, in fact, showed the best longtime stability (more than $3500 \mathrm{~h}$ ) and the lowest overpotential. The sample containing $\mathrm{Pyr}_{12 \mathrm{O} 1}$ TFSI showed almost the same cycling stability, failing due to lithium consumption only slightly earlier. As expected, the $\mathrm{Pyr}_{12 \mathrm{O} 1}$ FSI electrolyte did not work since the applied current, which value was selected to perform the test in a reasonable time frame, was higher than the maximum steady-state current found in the previous experiment. Pyr $_{14}$ FSI shows a very high overpotential - around $0.4 \mathrm{~V}$ - but the cells was cycled for more than $3000 \mathrm{~h}$. It is important to notice that, with the exception of the FSI-based ones, overvoltages lower than $0.4 \mathrm{~V}$ where observed for all other ternary electrolytes. This means that the plating-stripping tests were not affected by the massive electrochemical decomposition reactions previously discussed (see Fig. 7 and 8).

The two BETI-containing electrolytes showed performance very similar to the only TFSI-containing ones, however, with slightly higher overvoltages. In this case the $\mathrm{Pyr}_{1201}$-containing electrolyte failed much earlier (1400 h vs. $2800 \mathrm{~h})$. In the case of the $\mathrm{IM}_{14}$ anion, however, the opposite is observed with the $\mathrm{Pyr}_{12 \mathrm{O} 1}$-containing electrolyte showing superior performance than that with $\mathrm{Pyr}_{14}$. As expected from the results illustrated in Fig. 7, these electrolytes showed slightly higher overvoltages than those containing BETI and TFSI.

Impedance measurements were performed on all cells upon the lithium plating-stripping tests. Fig. 10 shows a few, selected impedance spectra for the ternary electrolytes containing the ionic liquids composed by the two cations and either TFSI or BETI anions. Within the frequency range investigated only the polymer electrolyte impedance and the interfacial impedance are concerned, without any contribution from ion diffusion impedance. While the electrolyte impedance of each cell (given by the high frequency intercept with the real axis) was practically unaffected by the repeated plating-stripping cycles, the interfacial resistance (given by the difference between the high and low frequency intercepts with the real axis) changed substantially. ${ }^{9}$ It is also remarkable as the interfacial resistance is, at least, one order of magnitude larger than the electrolyte resistance, which is in a full agreement with previous reports. ${ }^{9}$ Also remarkable is the initial decrease of the interfacial resistance observed with all polymer electrolytes, which has been already associated with a substantial reconstruction of the native SEI caused by the lithium deposition and plating. ${ }^{9}$ However, upon long-term cycling, the SEI is seen to
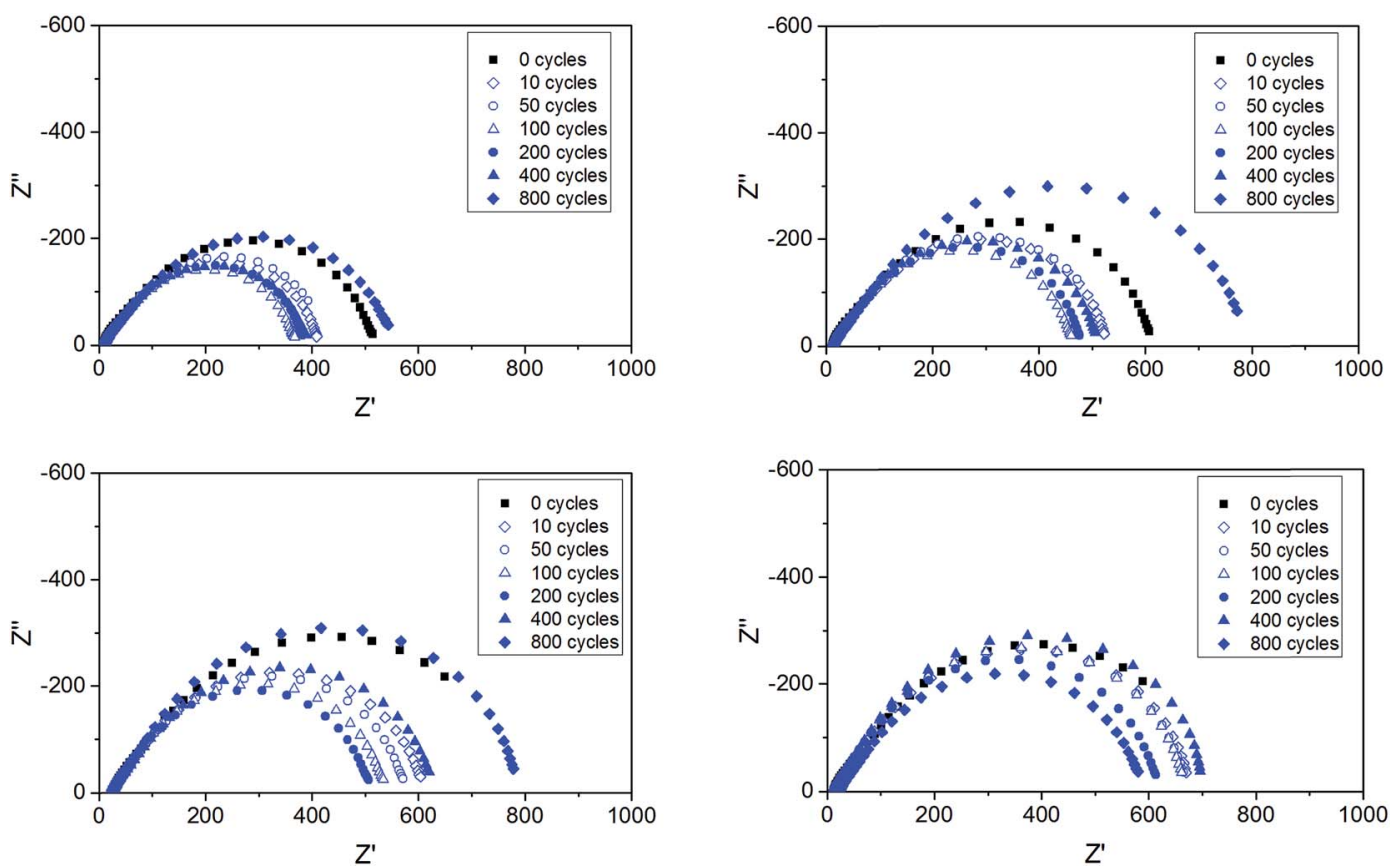

Fig. 10 Electrochemical impedance spectra of ternary electrolytes containing Pyr ${ }_{14} T_{F S S I}$ (left, top) and Pyr ${ }_{1201}{ }^{T F S I}$ (right, top), Pyr ${ }_{14} \mathrm{BETI}$ (left, bottom) and $\mathrm{Pyr}_{12 \mathrm{O}} \mathrm{BETI}$ (right, bottom) recorded at $21^{\circ} \mathrm{C}$ during the plating-stripping cycle test at $40{ }^{\circ} \mathrm{C}$. Frequency range: $100 \mathrm{kHz}-1 \mathrm{~Hz}$. 
grow with all polymer electrolytes. After 800 cycles the interfacial impedance was equal if not higher than that measured for the pristine cells. A minor effect of the different cations and anions is observed on the evolution of the interfacial impedance, with the TFSI anion and the $\mathrm{Pyr}_{14}$ cation leading to lower values.

\section{Conclusion}

Ternary polymer electrolytes were prepared with PEO, LiTFSI, and one of eight different ionic liquids, obtained from the combination of two cations $\left(\mathrm{Pyr}_{14}\right.$ and $\mathrm{Pyr}_{12 \mathrm{O} 1}$ ) and four anions (FSI, TFSI, BETI and $\left.\mathrm{IM}_{14}\right)$. For three of the four anions, the total ionic conductivity was increased with $\mathrm{Pyr}_{12 \mathrm{O} 1}$ compared to the corresponding $\mathrm{Pyr}_{14}$ ionic liquid. The ionic conductivity increased with smaller anions (FSI $>$ TFSI $>$ BETI $>$ IM $_{14}$ ). Samples with TFSI, BETI and $\mathrm{IM}_{14}$ were found to be fully amorphous. Though both electrolytes with FSI show the highest ionic conductivity, they also showed a partial crystallinity and lower thermal stability. Additionally, these electrolytes showed a dependence of their room temperature conductivity from the prior thermal history. Further investigation would be necessary to explain the surprising increase of the room temperature ionic conductivity (i.e., $20{ }^{\circ} \mathrm{C}$ ) after the cooling cycle (i.e., upon heating from $-40{ }^{\circ} \mathrm{C}$ ).

Chronoamperometry tests at $40{ }^{\circ} \mathrm{C}$ show as the polymer electrolytes comprising only TFSI or TFSI in a mixture with BETI or $\mathrm{IM}_{14}$ anions are capable of sustaining steady-state currents, i.e., which are associated to the mobility of $\mathrm{Li}^{+}$ions only, higher than $0.1 \mathrm{~mA} \mathrm{~cm}^{-2}$. This was not the case of FSI-containing electrolyte. A possible explanation for the poor performance of the latter might be the lower stability of the FSI anion resulting in the formation of thick SEI layers as well as the lower ability of the FSI anion to support the diffusion of $\mathrm{Li}^{+}$cations.

Long-time stripping-plating $\left(0.1 \mathrm{~mA} \mathrm{~cm}^{-1}\right.$ and $\left.40{ }^{\circ} \mathrm{C}\right)$ was shown feasible for seven of the eight electrolytes with cycling times ranging between 1400 and 3500 hour. In the impedance plots it can be observed that the resistance decreases during the first 100 (TFSI only) or 200 (BETI-containing) cycles. During further cycling the resistance increases again, reaching the initial resistance after around 800 cycles.

Summarizing, this comparative study shows as ternary polymer electrolytes can be made incorporating other pyrrolidinium cations than $\mathrm{Pyr}_{14}$, and imide anions than TFSI. However, no major improvements were achieved compared to the known systems composed of PEO, LiTFSI and Pyr ${ }_{14}$ TFSI.

\section{Acknowledgements}

The authors kindly acknowledge the financial support from the EU under the grant agreements no. 314282 (LISSEN - Lithium Sulfur Superbattery Exploitating Nanotechnology) and no. 608502 (SIRBATT - Stable Interfaces for Rechargeable Batteries).

\section{References}

1 (a) M. Armand, Solid State Ionics, 1994, 69, 309-319; (b) P. G. Bruce, S. A. Freunberger, L. J. Hardwick and J.-M. Tarascon, Nat. Mater., 2012, 11, 172-172.
2 (a) E. Peled, D. Golodnitsky, G. Ardel and V. Eshkenazy, Electrochim. Acta, 1995, 40, 2197-2204; (b) A. M. Christie, A. Lisowska-Oleksiak and C. A. Vincent, Electrochim. Acta, 1995, 40, 2405-2411; (c) J. K. Stark, Y. Ding and P. A. Kohl, J. Electrochem. Soc., 2013, 160, D337-D342.

3 M. Armand, Adv. Mater., 1990, 2, 278-286.

$4 \mathrm{~W}$. Gorecki, M. Jeannin, E. Belorizky, C. Roux and M. Armand, J. Phys.: Condens. Matter, 1995, 7, 6823.

5 bluecar.fr, 2014.

6 M. Watanabe and T. Mizumura, Solid State Ionics, 1996, 8688(1), 353-356.

7 J.-H. Shin, W. A. Henderson and S. Passerini, Electrochem. Commun., 2003, 5, 1016-1020.

8 M. Joost, M. Kunze, S. Jeong, M. Schönhoff, M. Winter and S. Passerini, Electrochim. Acta, 2012, 86, 330-338.

9 G. B. Appetecchi, G. T. Kim, M. Montanino, F. Alessandrini and S. Passerini, J. Power Sources, 2011, 196, 6703-6709.

10 A. S. Shaplov, P. S. Vlasov, M. Armand, E. I. Lozinskaya, D. O. Ponkratov, I. A. Malyshkina, F. Vidal, O. V. Okatova, G. M. Pavlov, C. Wandrey, I. A. Godovikov and Y. S. Vygodskii, Polym. Chem., 2011, 2, 2609-2618.

11 H. Hu, W. Yuan, L. Lu, H. Zhao, Z. Jia and G. L. Baker, J. Polym. Sci., Part A: Polym. Chem., 2014, 52, 2104-2110.

12 (a) Z. Jia, W. Yuan, H. Zhao, H. Hu and G. L. Baker, RSC Adv., 2014, 4, 41087-41098; (b) M. Döbbelin, I. Azcune, M. Bedu, A. Ruiz de Luzuriaga, A. Genua, V. Jovanovski, G. Cabañero and I. Odriozola, Chem. Mater., 2012, 24, 1583-1590.

13 M. Joost, G. T. Kim, M. Winter and S. Passerini, Electrochim. Acta, 2013, 113, 181-185.

14 (a) M. Kunze, S. Jeong, E. Paillard, M. Winter and S. Passerini, J. Phys. Chem. C, 2010, 114, 12364-12369; (b) M. Kunze, E. Paillard, S. Jeong, G. B. Appetecchi, M. Schönhoff, M. Winter and S. Passerini, J. Phys. Chem. C, 2011, 115, 19431-19436; (c) M. Kunze, S. Jeong, E. Paillard, M. Schönhoff, M. Winter and S. Passerini, Adv. Energy Mater., 2011, 1, 274-281; (d) J. Reiter, E. Paillard, L. Grande, M. Winter and S. Passerini, Electrochim. Acta, 2013, 91, 101-107.

15 J.-H. Shin, W. A. Henderson and S. Passerini, J. Electrochem. Soc., 2005, 152, A978-A983.

16 Q. Zhou, W. A. Henderson, G. B. Appetecchi, M. Montanino and S. Passerini, J. Phys. Chem. B, 2008, 112, 13577-13580.

17 J. Huang and A. F. Hollenkamp, J. Phys. Chem. C, 2010, 114, 21840-21847.

18 M. B. Armand, P. G. Bruce, M. Forsyth, B. Scrosati and W. Wieczorek, in Energy Materials, ed. D. Bruce, D. O'Hare and R. I. Walton, Wiley, 2011, pp. 1-31.

19 (a) E. Peled, J. Electrochem. Soc., 1979, 126, 2047-2051; (b) Z. Li, J. Huang, B. Yann Liaw, V. Metzler and J. Zhang, J. Power Sources, 2014, 254, 168-182; (c) D. Lv, Y. Shao, T. Lozano, W. D. Bennett, G. L. Graff, B. Polzin, J. Zhang, M. H. Engelhard, N. T. Saenz, W. A. Henderson, P. Bhattacharya, J. Liu and J. Xiao, Adv. Energy Mater., 2014, DOI: 10.1002/aenm.201400993. 